\title{
Recurrent and Drastic Increase in Dabigatran Levels May Be Induced by Therapeutic Plasma Exchange
}

\author{
Marc A. Pflug, Peter D. Schellinger \\ Department of Neurology and Neurogeriatrics, Johannes Wesling Medical Center Minden, University Clinic RUB, Minden, Germany
}

\section{Dear Sir:}

We present the case of a 76-year-old man, who received plasma exchange (PE) after initially being treated with intravenous immunoglobulins for severe Guillain-Barré-Strohl syndrome. He had been on regular oral anticoagulants with dabigatran $110 \mathrm{mg}$ twice a day for prevention of stroke and systemic embolism because of non-valvular atrial fibrillation.

Dabigatran was paused in the evening before the day of lumbar puncture and continued in the evening of hospital day 3. Table 1 shows the administration scheme for anticoagulants. Shortly before the first PE, partial thromboplastin time (PTT) was 69 seconds, and international normalized ratio (INR) was 1.40. No other anticoagulant was administered after the onset of the first PE (Table 1).

On the first day after $\mathrm{PE}$, coagulation parameters changed to an INR $>5.0$ and PTT of 166 seconds (Table 1). A control later that day confirmed those values (INR >5.0; PTT >200 seconds). This time, thrombin time (T) was $>200$ seconds. Dabigatran levels, derived from the ecarin clotting time, which "provide(s) a direct measure of the activity of direct thrombin inhibitors,"1 was measured, yielding an elevation beyond the measurable value (>460 $\mathrm{ng} / \mathrm{mL}$ ). Since the patient showed active signs of gastrointestinal bleeding and bleeding from catheter insertion sites, he received idarucizumab (Praxbind ${ }^{\oplus}$, Boehringer Ingelheim Pharmaceuticals, Ingelheim, Germany) $5 \mathrm{~g} / 100 \mathrm{~mL}$ and intravenous vitamin $\mathrm{K} 10 \mathrm{mg}$ after undergoing a second PE. Later that day, there was no measurable level of dabigatran found, and INR (1.90), PTT (54 seconds), and TT (15.5 seconds) were stable.

After a third PE on the next day, dabigatran levels rapidly increased again to $142 \mathrm{ng} / \mathrm{mL}$, and coagulation parameters changed accordingly (INR, 3.91; PTT, 107 seconds; $\Pi>200$ seconds). The next day, dabigatran levels kept increasing $(163 \mathrm{ng} / \mathrm{mL})$, and the patient continued showing active signs of bleeding from catheter insertion and gastrointestinal sites. It was decided to provide another infusion of $5 \mathrm{~g} / 100 \mathrm{~mL}$ idarucizumab (Praxbind ${ }^{8}$ ) and intravenous vitamin $\mathrm{K} 10 \mathrm{mg}$. Later that day, no measurable level of dabigatran was found $(<15 \mathrm{ng} / \mathrm{mL})$.

Once again, after a fourth PE the next day, the dabigatran level was $32 \mathrm{ng} / \mathrm{mL}$ in the evening and increased to $47 \mathrm{ng} / \mathrm{mL}$ the next morning. $\Pi$ was 69.9 and 75.6 seconds in the evening and next morning, respectively. Meanwhile, the patient showed no active signs of bleeding. Therefore, no third dose of idarucizumab was administered. In the following days, dabigatran levels slowly decreased while PE was paused. On hospital day 7, the anticoagulants were discontinued.

To the best of our knowledge, this is the first case of excessive anticoagulation due to dabigatran in a patient undergoing $\mathrm{PE}_{\text {, }}$ with accordingly altered coagulation parameters, including high dabigatran levels, and repeated clinically relevant bleeding despite drug discontinuation and administration of the specific antidote twice. The close and repeated timely correlation to the PEs and recurrence shortly after being administered with idarucizumab suggests that PE mobilizes dabigatran. Dabigatran generally shows "low (34\% to 35\%) concentration-independent binding of dabigatran to human plasma proteins" and is mainly stored in body water and moderately in body tissue.' Pre-existing accumulation of dabigatran in extravascular compartments may be linked to initially moderate and later severe renal impairment in an elderly patient who is critically ill at the time of PE. Severe renal impairment and old age are associated with significantly elevated dabigatran plasma levels. ${ }^{1}$ The patient received no drugs that are known to elevate dabigatran plasma levels.'

Since impairment of thrombin activity also affects the endpoints of the intrinsic and extrinsic parts of the blood coagulation cascade, there are unspecific changes to other coagulation parameters. No other cause of significant bleeding, i.e., signifi- 
Table 1. Laboratory findings of patient on days after administration

\begin{tabular}{|c|c|c|c|c|c|c|c|c|c|}
\hline & INR & PTा & $\Pi$ & Dab & $\mathrm{CrCl}$ & $\mathrm{Fib}$ & Plt & Anticoagulant agent & Plasma exchange \\
\hline Day 0 & 1.41 & 51 & & & 40 & & 204 & Dabigatran per oral $110-0-110 \mathrm{mg}$ & \\
\hline Day 1 & & & & & & & & Dabigatran per oral $110-0-0 \mathrm{mg}$ & \\
\hline Day 2 & & & & & & & & None & \\
\hline Day 3 & & & & & & & & Dabigatran per oral 0-0-110 mg & \\
\hline Day 4 & & & & & & & & Dabigatran per oral $110-0-110 \mathrm{mg}$ & \\
\hline Day 5 & 1.37 & 38 & & & 44 & & 211 & $\begin{array}{l}\text { Dabigatran per oral } 110-0-0 \mathrm{mg} \\
\text { Enoxaparin subcutaneous } 0-0-60 \mathrm{mg}\end{array}$ & \\
\hline Day 6 & 1.35 & 43 & 47.5 & & 38 & & 179 & Enoxaparin subcutaneous $60-0-0 \mathrm{mg}$ & \\
\hline Day 7 & 1.40 & 69 & & & 28 & 404 & 144 & Heparin intravenous & 03:30 PM-05:00 PM \\
\hline Day 8 04:36 AM & $>5$ & 166 & & & 30 & 232 & 152 & None & 10:30 AM-12:00 AM \\
\hline Day 8 04:50 PM & $>5$ & $>200$ & $>200$ & $>460$ & 28 & 138 & 149 & None & \\
\hline Day 8 11:32 PM$^{*}$ & 1.90 & 54 & 15.5 & $<15$ & & 184 & 137 & None & \\
\hline Day 9 09:40 AM & 2.08 & 78 & 15.9 & $<15$ & 24 & 248 & 152 & None & 09:30 AM-11:00 AM \\
\hline Day 9 06:14 PM & 3.91 & 107 & $>200$ & 142 & & 141 & & None & \\
\hline Day 10 05:50 AM & 2.54 & 98 & $>200$ & 163 & 26 & 220 & 121 & None & \\
\hline Day 10 07:05 $\mathrm{PM}^{+}$ & 1.30 & 44 & 14.5 & $<15$ & & & & None & \\
\hline Day 11 06:09 AM & 1.24 & 71 & 26.1 & $<15$ & 27 & 322 & 121 & None & 10:30 AM-12:00 AM \\
\hline Day 11 07:56 PM & 1.84 & 58 & 69.9 & 32 & & 158 & & None & \\
\hline Day 12 & 1.65 & 59 & 75.6 & 47 & 28 & & 138 & None & \\
\hline Day 13 & 1.49 & 60 & 74.2 & 39 & 25 & 271 & 119 & None & \\
\hline Day 14 & 1.39 & 49 & 55.6 & 29 & 26 & 267 & 122 & None & 02:00 PM-03:30 PM \\
\hline Day 15 & 1.59 & 42 & 37.0 & $<15$ & 28 & 158 & 150 & None & \\
\hline Day 18 & 1.20 & 38 & 30.1 & $<15$ & 32 & 304 & 162 & Enoxaparin subcutaneous $0-0-40 \mathrm{mg}$ & \\
\hline
\end{tabular}

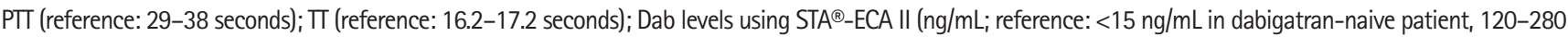
$\mathrm{ng} / \mathrm{mL} 2$ hours after administration, 60-140 ng/mL at trough level [12 hours after administration]); $\mathrm{CrCl}$ measured by using CKD-EPI-formula (mL/min; reference: 80-140 mL/min); Fib levels, Clauss method (mg/dL; reference: 190-430); Plt (g/L; reference: 150-400); anticoagulant agent, scheme of any anticoagulant agent on the given day; heparin, continuous intravenous unfractionated heparin $25.000 \mathrm{IE} / 50 \mathrm{~mL}$, infusion rate: 1,6 mL/hr, started 06:00 AM, discontinued: 04:00 PM. INR, international normalized ratio; PT, partial thromboplastin time; $\Pi$, thrombin time; Dab, dabigatran; $\mathrm{CrCl}$, creatinine clearance; Fib, fibrinogen; PIt, platelets. ${ }^{*}$ After first administration of idarucizumab $5 \mathrm{~g} / 100 \mathrm{~mL}$ intravenous; ${ }^{+}$After second administration of idarucizumab $5 \mathrm{~g} / 100 \mathrm{~mL}$ intravenous.

cantly reduced fibrinogen or platelet levels, liver failure, or other toxic influences on coagulation were identified.

A recent report indicated that patients might benefit from PE when experiencing bleeding at toxic dabigatran levels. ${ }^{2}$ The underlying limitations in comparing those cases are the difference in the patient age, difference in drug dosage, and lack of data for coagulation parameters after PE in the previous article.

We concluded that patients with the use of dabigatran with or without underlying risk factors, such as age, renal impairment, or comedication, should be closely monitored for a sudden and lasting elevation of dabigatran levels while undergoing PE.

\section{References}

1. European Medicines Agency. Pradaxa product information. https://www.ema.europa.eu/en/documents/product-information/pradaxa-epar-product-information_en.pdf. 2009. Ac- cessed May 19, 2020.

2. Kamboj J, Kottalgi M, Cirra VR, Shah N, Kamboj R. Direct thrombin inhibitors: a case indicating benefit from 'plasmapheresis' in toxicity: a call for establishing "guidelines" in overdose and to find an "antidote"! Am J Ther 2012;19:e182-e185.

Correspondence: Marc A. Pflug

Department of Neurology and Neurogeriatry, Johannes Wesling Medical Center Minden, Hans-Nolte-Straße 1, 32429 Minden, Germany

Tel: +49-571-790-3501

Fax: +49-571-790-293500

E-mail:marc.pflug@rub.de

Received: December 27, 2019

Revised: April 9, 2020

Accepted: May 18, 2020

Peter D. Schellinger received honoraria (advisory boards, speaker fees) and travel grants from Boehringer Ingelheim, the manufacturer of dabigatran and idarucizumab. Marc A. Pflug declares having no conflict of interest. 